Carolina Dantas Veloso de Araújo

Mudança Organizacional, Cultura e Formação de Novas Equipes: Analisando o Caso da Aquisição da Lamson pela Energy Global

Trabalho de Conclusão de Curso

CENTRO de CIÊNCIAS SOCIAIS - CCS

DePARTAMENTO de AdMINISTRAÇÃo

Graduação em Administração de Empresas 
Carolina Dantas Veloso de Araújo

\title{
Mudança Organizacional, Cultura e Formação de Novas Equipes: Analisando o Caso da Aquisição da Lamson pela Energy Global
}

\author{
Trabalho de Conclusão de Curso
}

Trabalho de Conclusão de Curso, apresentado ao programa de graduação em Administração da PUCRio como requisito parcial para a obtenção do título de graduação em Administração.

Orientadora: Flávia Cavazotte

Rio de Janeiro, Novembro de 2017. 
Ficha catalográfica 


\section{Agradecimentos}

Gostaria de agradecer a todos que colaboraram com o desenvolvimento deste trabalho e tornaram esta experiência possível. Meus pais que sempre me apoiaram e me inspiram a fazer o meu melhor. Ao Guilherme que sempre acreditou em mim e que esteve ao meu lado em todos os momentos. A professora Flávia Cavazotte que me ajudou durante todo o caminho e me orientou da melhor forma possível. A todos os entrevistados que contribuíram com este trabalho e que me ajudaram. 


\section{Resumo}

Araújo, Carolina Veloso. Mudança Organizacional, Cultura e Formação de Novas Equipes: Analisando o Caso da Aquisição da Lamson pela Energy Global. / Carolina Veloso de Araújo; orientadora: Flávia Cavazotte - Rio de Janeiro: PUC, Departamento de Administração, 2017. V., 46p.

Este trabalho teve como objetivo realizar um estudo sobre o grau de integração cultural entre as empresas Energy Global e Lamson após o processo de aquisição da segunda empresa. Para tanto, foi realizado um estudo de caso e uma pesquisa exploratória para analisar o processo de formação de novas equipes, assim como compreender a estratégia de integração adotada pela empresa adquirente. As entrevistas foram baseadas nos modelos de formação de equipes de Marks e Mirvis (1992), em que foram entrevistadas duas equipes com membros de ambas as empresas, e o modelo de Estratégias de Integração Cultural de Barros (2003), em que foi entrevistado um gerente de Recursos Humanos. Os resultados mostraram que as pessoas que vieram da mesma empresa que pertencem a mesma equipe, trabalham de forma integrada superior comparadas as pessoas que vieram de empresas diferentes e que trabalham na mesma equipe. Além disso, a estratégia de integração percebida na análise foi a de grau de mudança baixo da empresa adquirente e grau de mudança elevado para a empresa adquirida.

\section{Palavras-chave}

Cultura organizacional. Aquisição. Integração. Novas Equipes 


\section{Abstract}

Araújo, Carolina Dantas Veloso de. Organizational Change, Culture and the Formation of New Teams: Analysing the Case of the Acquisition of Lamson by Energy Global. Rio de Janeiro, 2017. 46p. Dissertation Departamento de Administração, Pontifícia Universidade Católica do Rio de Janeiro.

This work has the purpose to study the degree of cultural integration between the companies General Electric and Alstom after the acquisition process of the second company. In order to do so, a case study and an exploratory research were carried out to analyze the formation process of new teams, as well as to understand the integration strategy adopted by the acquiring company. The interviews were based on the team building model from Marks and Mirvis (1992), in which two teams were interviewed with members of both companies and the Cultural Integration Strategies model from Barros (2003), in which a Human Resources manager was interviewed. The results showed that people who came from the same company that belong to the same team, work in an integrated form superior than compared to people who came from different companies and who work in the same team. In addition, the integration strategy perceived in the analysis was that the degree of change of the acquirer company was low and the degree of change of the acquired company was high.

\section{Key words}

Organizational Culture. Acquisition. Integration. New Teams. 


\section{Sumário}

1. Introdução ao tema e ao problema do estudo 6

$\begin{array}{ll}\text { 1.1. Objetivo do estudo } & 7\end{array}$

1.2. Objetivos intermediários do estudo $\quad 7$

1.3. Delimitação e foco do estudo

1.4. Relevância do Estudo 8

2. Referencial Teórico 9

2.1. Fusões e aquisições 9

2.2. Histórico Global 11

2.2.1. F\&A no Brasil 12

2.3. Cultura organizacional 13

2.3.1. Conceito de Aculturação 13

2.3.2. O conceito de Fit Estratégico 14

2.4. Estratégias de Aculturação 15

2.5. Mudanças nas equipes após F\&A 17

2.5.1. Etapas para a formação de novas equipes 18

2.6. Modelos Escolhidos para Aplicação da Pesquisa 20

3. Metodologia 21

3.1. Seleção do Caso 22

4. Análise $\quad 24$

4.1. A Aquisição 24

4.2. Análise dos Resultados $\quad 24$

4.2.1. 1aㅡ Dimensão - Papel do líder 25

4.2.2. $2^{\mathrm{a}}$ Dimensão: Problemas enfrentados pelos membros da equipe 26

4.2.3. 3ㅁ Dimensão: Fontes de Resistência 28

4.2.4. 4ª Dimensão: Combatendo a Resistência 31

4.3. Síntese dos Resultados 32

4.4. Análise da Entrevista com Gerente de Recursos Humanos da EG 34

$\begin{array}{ll}\text { 4.5.Discussão e Considerações finais } & 37\end{array}$

5. Conclusão 38

6. Referências Bibliográficas $\quad 40$

Apêndice: Roteiro do Questionário das Entrevistas 42 


\section{Lista de Figuras}

Figura 1 - Estratégias de Aculturação de Berry 16

Figura 2 - Estratégias de Integração Cultural de Barros 16

Figura 3 - Os estágios na formação de novas equipes em F\&A 19

Figura 4 - Perfil dos entrevistados 22

Figura 5 - Resumo dos resultados da Equipe A 33

Figura 6 - Resumo dos resultados da Equipe B 34

Figura 7 - Descobertas do Programa Peers to Peers 36 


\section{1 \\ Introdução ao tema e ao problema do estudo}

Como organizações estão inseridas em ambientes de mudanças frequentes, seus recursos e competências são reconfigurados a medida de que estas empresas precisam manter suas vantagens competitivas ou buscar novas soluções para sobrevivência. Por isso, de acordo com Amit \& Schoemaker (1993), é necessário a antecipação destas transformações.

Dentro deste cenário, uma alternativa encontrada pelas organizações para sobreviver as mudanças constantes no ambiente e para alavancar sua vantagem competitiva, foi por meio de fusões e aquisições, que segundo Porter (1995) este processo pode trazer as empresas diferenciação ou liderança de custos. A estratégia de aquisição garante as organizações vantagem competitiva quando há integração entre as partes para produzirem e desenvolverem soluções que não seriam possíveis de serem realizadas com outras empresas (Santos \& Tomei, 2015). Estes mesmos autores descrevem aquisições como estratégias de compra integral ou participação de controle de uma empresa por outra empresa com o intuito de gerar uma competência mais eficiente e tornar a empresa adquirida parte de seu portfólio.

Com a globalização, abertura de mercados e pressões externas, as empresas buscam por inovações e oportunidades do mercado para alavancarem suas operações, combinações entre empresas ganharam força, a partir da premissa de que há necessidade de crescimento global e aumento de portfólio oferecido pelas organizações. Para efetuar de fato tal estratégia, o processo de fusão e aquisição é longo, complexo e possui diversos passos até sua concretização. É necessário analisar o cenário, sua viabilidade e montar um modelo organizacional para a nova empresa (Rhinow, 2006).

Uma forma utilizada para avaliar o desempenho de uma fusão ou aquisição é a partir dos resultados financeiros gerados, porém, é necessário analisar a integração das duas empresas após a união para que esta avaliação seja eficiente e que os resultados reflitam a sinergia entre ambas empresas. Muitas fusões não são capazes de obter resultados positivos ao longo do tempo devido a uma falta de integração nas culturas organizacionais e, de acordo com 
os autores Nahavandin e Maleqzadeh (1998), o sucesso pode ser alcançado quando as duas empresas apresentam sinergias culturais. Por isso, os valores organizacionais de uma nova empresa, criada a partir de uma fusão, que influenciam muitos dos processos e das estratégias precisam estar claros e definidos para não haver conflitos.

Visto isto, este trabalho busca compreender as mudanças causadas devido à aquisição da empresa Lamson pela Energy Global na formação de novas equipes e na cultura organizacional da empresa.

\section{1}

\section{Objetivo do estudo}

Analisar a estratégia de integração e as mudanças causadas no processo de formação de novas equipes com a aquisição da empresa Lamson pela Energy Global.

\section{2}

\section{Objetivos intermediários do estudo}

Os objetivos intermediários deste trabalho são: 1) Escolha da Framework de Barros (2003) e Marks \& Mirvis (1992) a partir da literatura; 2) Desenvolvimento de questionário com base na Framework escolhida; 3) Aplicação da Framework para avaliação do caso da aquisição.

\section{3}

\section{Delimitação e foco do estudo}

Neste trabalho, serão abordados os temas de cultura organizacional, estratégias de integração e mudanças geradas a partir de processos de Fusões e Aquisições nas equipes. Além disso, o autor estudará o processo de 
integração entre as duas empresas que se uniram e seus impactos para os funcionários. Não será abordado o impacto financeiro no lucro da empresa.

\section{4}

\section{Relevância do Estudo}

As razões para realizar este estudo vieram da oportunidade de fazer uma análise sobre fusões e aquisições de empresas de grande porte e seus impactos após o acordo, pois não há muitos trabalhos de pesquisa sobre este tema no Brasil. O estudo visa contribuir com análises e sugestões para a empresa adquirente, Energy Global, sobre como seus colaboradores reagiram com a fusão. Além disso, o autor possui interesse neste assunto visto que atualmente trabalha nesta empresa e está passando por um processo de fusão no momento com outra organização. 


\section{2 \\ Referencial Teórico}

\section{1}

\section{Fusões e aquisições}

A estratégia de Fusão e Aquisição é muitas vezes definida como se estes dois métodos de combinação empresarial fosse o mesmo. Porém, é importante ressaltar que fusão e aquisição possuem definições distintas. De acordo com Marks \& Mirvis (2001), o primeiro método, a fusão, ocorre quando o resultado da união de duas ou mais empresas independentes é a criação de uma nova organização.

Este processo é comum em empresas do mesmo porte e que atuam em mercados similares, que deixam de existir para que a nova organização seja criada. Há definições que indicam que a nova empresa, formada pela fusão, concederá ás organizações o mesmo percentual de participação (Frensch, 2007), porém este argumento não pode ser considerado para todos os casos.

Existem diferentes tipos de classificação para explicar o processo de uma fusão, a primeira é a fusão vertical que acontece quando empresas de diferentes níveis de produção decidem unirem-se para obterem diversos benefícios como diminuir seus custos devido ao fácil acesso a matéria-prima, melhorias na distribuição de mercadorias e aumento de controle das atividades (Levy \& Sarnat 1988).

Outra forma de fusão é a horizontal, que de acordo com Gitman (1997) empresas que atuam dentro de um mercado ou que sejam até mesmo concorrentes entre si, unem-se para crescer sua participação de mercado e para ganhar economias de escala quando há ampliação na fabricação de produtos.

Por último, as fusões podem ocorrer entre empresas que não possuem semelhanças de produto tampouco de área de atuação. Esta classificação chama-se de fusão conglomerada que é vista por Weston (1990) como vantajosa quando a intenção é a de maximizar os lucros por meio de investimentos diversificados que não seriam possíveis de acontecer dentro do mercado limitado em que as organizações estavam inseridas. 
Já o segundo método de combinação organizacional, a aquisição, consiste na compra de uma empresa por outra, em que a adquirida torna-se parte da organização compradora que decidirá se a empresa comprada poderá manter sua identidade ou não. Segundo Tanure e Cançado (2005), a entidade adquirida perde sua identidade legal após a aquisição.

Assim como as fusões possuem suas características, as aquisições também apresentam as suas. A literatura aponta três fases que passam pelo processo de uma aquisição, a primeira delas é quando a empresa compradora analisa diversas informações da adquirida, como relatórios financeiros, legais e operacionais. Esta etapa chama-se de Due Diligence segundo Tanure \& Cançado (2005).

Passada esta fase, a próxima é a de negociação, onde os líderes planejam a estrutura organizacional que será implementada com a aquisição e os planos de ação a serem seguidos. Por fim, a integração é a última parte deste processo e determinará o sucesso ou fracasso da estratégia de combinação empresarial entre as organizações, pois será nesta fase que o alinhamento cultural terá o maior impacto (Tanure \& Cançado, 2005).

Os motivos pelos quais estas estratégias são adotadas podem ser explicados por diversos autores, segundo Gitman (1997), aumentar os lucros aos acionistas é uma das principais razões. Para o mesmo, existem também outros objetivos como crescimento de Market Share e portfólio, assim como obtenção de um maior conhecimento de gestão administrativa e de recursos tecnológicos. Há autores que indicam que o surgimento das fusões e aquisições foi uma consequência do mercado capitalista, Cano, em 2002, definiu que:

Os processos de F\&A's são inerentes à concorrência capitalista. Acumulação de capital, inovações, ganhos de produtividade e acirramento da competição, levando a pressões pela eliminação de concorrentes ou pela abertura de novos mercados, são processos que marcaram a história do capitalismo desde o seu início (Cano, 2002). 


\section{2 Histórico Global}

Durante o século $X X$, grande parte da riqueza dos Estados Unidos foi composta pelas 200 maiores empresas que passaram por fusões, e que até 1930 houve 4600 fusões entre organizações no país (Wasserstein, 2000). Outro acontecimento neste período, foi o fato de que os tribunais americanos incentivarem a junção entre empresas, contrapondo a legislação estabelecida e possibilitando a união de grandes organizações (Marks \& Mirvis, 2001). Ainda de acordo com o autor Wasserstein (2000), em 1960, as 200 maiores empresas nos EUA eram responsáveis por $60 \%$ do mercado industrial que consequentemente colaborou para a formação dos conglomerados.

Oportunidades financeiras passaram a caracterizar as fusões e aquisições a partir de 1970, quando grandes empresas investiram bilhões na compra de novos acordos. Este momento marcou uma mudança no comportamento das empresas, pois as fusões passaram a ser adotadas por organizações consideradas tradicionais e conservadoras, que tiveram que se adaptar aos novos modelos de gestão com a aquisição de outras empresas (Marks \& Mirvis, 1998).

A década de 1980 é considerada marcante ao visto que novas oportunidades se destacaram com o surgimento de novas tecnologias, informática e a troca de informação de forma acelerada. Dessa forma, o mercado se adaptou e muitas cadeias industrias foram reestruturadas. De acordo com o Homem et al. (2009), 25\% das empresas nos EUA participaram de fusões ou aquisições, tal movimento foi influenciado através dos incentivos de financiamentos. Já os anos de 1990 foram marcados por fusões entre grandes companhias do mesmo porte, intensificando as transações de alto volume financeiro.

O Instituto Thompson Reusters demonstrou uma análise deste aumento no tamanho destas operações durante o final do século $X X$ até o início do século XIX. Em 1999, os acordos entre as organizações eram de US\$2,3 trilhões, e passou para US\$ 3,6 trilhões em 2000, quando mais de 30.000 fusões e aquisições foram estabelecidas. Estes números foram em sua maior parte originados dos Estados Unidos, em que 50\% destas transações ocorreram.

Os próximos anos não apresentaram o mesmo crescimento em relação a fusões como o ano 2000, alguns fatores podem explicar tal observação, como o 
"estouro" da bolha da Internet que fez com que os valores de muitas ações de empresas deste setor caíssem; o monopólio de empresas que dificultou novos acordos e o ataque terrorista de 11 de setembro que gerou instabilidade tanto nos Estados Unidos quanto no restante do mundo. Porém, em 2005 houve novos investimentos com a melhora no mercado de capitais, onde as empresas voltaram a financiar suas oportunidades de aquisição ou fusão com outras empresas (Thomson Reuters, 2017).

\subsection{1}

\section{F\&A no Brasil}

No Brasil, a trajetória de crescimento das fusões e aquisições ocorreu de forma diferente. Somente nos anos 90 que o país começou a apresentar mudanças em relação a estratégias empresarias baseadas no mercado americano, seguindo o exemplo das organizações do exterior que já adotavam os processos de combinação empresarial. O governo brasileiro incentivou por muitos anos apenas a indústria nacional e as empresas estatais, não havia grande presença de organizações internacionais.

Esta mudança ocorreu quando o governo diminuiu as barreiras de entrada para o mercado internacional, e segundo Héau (2001) foi possível aumentar o número de privatizações no Brasil em setores como telecomunicações e transporte, e com isso incentivar o processo de fusão e aquisição entre empresas. Neste período, nota-se um aumento de investimento por parte de organizações estrangeiras no país que acreditavam no crescimento econômico do Brasil, possibilitando a entrada de mais concorrentes, muitos destes originados de F\&A's. Como forma de reflexo, as empresas brasileiras passaram a adotar esta estratégia (Cano, 2002). 


\section{3 \\ Cultura organizacional}

O conceito de Cultura Organizacional surgiu em 1930 quando pesquisadores começaram a realizar trabalhos para entender o comportamento humano nas empresas. Existem diversos aspectos que descrevem a cultura organizacional de uma firma, como suas crenças, ideologias e valores. Este último termo, é utilizado na literatura dentro do contexto de cultura para explicar o que influencia o comportamento humano nas organizações (Russo, 2010). Para Schein (1990), os valores são estabelecidos a partir do momento em que a empresa obtém sucesso e os funcionários aprendem juntos a como agir da forma correta:

Cultura organizacional é um padrão de pressupostos básicos compartilhados que um grupo aprendeu ao resolver seus problemas de adaptação externa e integração interna e que funcionou bem o sufi ciente para ser considerado válido e ensinado a novos membros como a forma correta de perceber, pensar e sentir com relação a esses problemas (Schein, 1990).

A relevância do estudo da cultura organizacional cresce cada vez mais, pois os membros das lideranças das empresas conseguem observar como uma cultura forte e bem definida contribui para o cumprimento de metas e objetivos, levando seus colaboradores a mesma direção. Além disso, Russo (2010) observou que o comportamento dos funcionários é influenciado por um determinado "perfil" que se encaixa na cultura da empresa e que é fundamental para a elaboração estratégica de gestão da empresa.

\subsection{1 \\ Conceito de Aculturação}

Dentro da literatura existem diversos estudos que abordam temas sobre cultura organizacional e seus processos de mudança. Um conceito que descreve o momento em que duas culturas são interligadas, é a aculturação. (Cooper, 1993).

Uma das primeiras definições de aculturação foi descrita como: "aculturação é o fenômeno resultante de um encontro contínuo de grupos de 
indivíduos que possuem culturas diferentes, em que a cultura original de um dos grupos ou de ambos é alterada" (Linton, 1936). Para Berry (1997), é importante ressaltar que o impacto nas culturas das organizações será mais profundo para uma e menos para a outra.

\subsection{2 \\ O conceito de Fit Estratégico}

O conceito de Fit Estratégico está presente na literatura teórica de Andrews (1971) e Chandler (1962) e possui sua origem na ideia de alinhar os recursos organizacionais de uma empresa tanto com as oportunidades encontradas no ambiente externo quanto com suas ameaças. Para Zajac \& Bresser (2000), para alcançar uma estratégia de alinhamento Fit é preciso identificar quais oportunidades do ambiente externo podem causar impactos de mudança na estratégia da companhia, por isso esse fator possui relevância na tomada de decisão para as lideranças das empresas ao considerar investir em uma F\&A.

Há estudiosos, como Lubatkin (1983), que indicam que o sucesso de uma F\&A será atingido por meio do alinhamento fit estratégico cultural entre as duas empresas. Este alinhamento não será o mesmo para todas as combinações organizacionais e cada uma terá um nível diferente de adesão. Para Lubatkin, quanto maior for o nível de alinhamento, mais chance a nova companhia terá de melhorar sua performance. Além disso, uma estratégia bem-sucedida entre organizações que possuem características similares, tende a criar mais valor aos stakeholders e possibilitam a transferência de habilidades primordiais de uma empresa para a outra (Lubatkin \& Montgomery, 1988). 


\section{4 \\ Estratégias de Aculturação}

John Berry escreveu um estudo e desenvolveu um modelo em 1997, que analisa as estratégias que podem ser adotadas em um processo de aculturação. Primeiro, ele divide o cenário em dois casos, sendo um deles quando o objetivo é o de manter a identidade cultural e suas características e o outro quando há contato e participação em outros grupos culturais. O modelo abaixo é utilizado para identificar quatro possíveis estratégias de aculturação quando os dois cenários em questão acontecem simultaneamente. Outro ponto relevante é o de escolher um grupo para analisar a estratégia, o grupo dominante ou nãodominante.

No ponto de vista do grupo não-dominante, quando não há a necessidade de manter a cultura original e sim a interação com a outra cultura, a estratégia de Assimilação é estabelecida. Por outro lado, quando este grupo deseja manter sua identidade cultural e evitam contato com os demais, será definida a estratégia de Separação. Porém, a partir do momento em que há interesse em manter a cultura do grupo e ao mesmo tempo interagir com os outros grupos de culturas distintas, a opção de estratégia é a de Integração. Por último, a estratégia de Marginalização ocorre quando não há a possibilidade de continuar com a cultura original, devido a perda da cultura, e tampouco interesse em relacionar-se com os outros, por motivos de exclusão ou discriminação (Berry 1997).

Para identificar e analisar as estratégias do grupo Dominante, outros termos são utilizados. A estratégia de Separação descrita acima, quando é imposta pelo grupo Dominante, chama-se de Segregação. A ideia de Assimilação, sendo forçada pelos dominantes torna-se "panela de pressão". Já no caso da Marginalização, é raro que esse método seja escolhido, sendo comum acontecer como uma consequência da pressão exercida pelo grupo dominante ou pela exclusão dos membros do grupo quando há segregação.

A Integração é possível de ser bem-sucedida quando a diversidade cultural é o objetivo principal e o grupo dominante é aberto e inclusivo, neste caso a estratégia é a de Consenso Mútuo entre os grupos de aceitar que devem conviver como pessoas de diferentes culturas. Para tanto, os dominantes reconhecem a importância da adaptação para atender as necessidades de todos. 


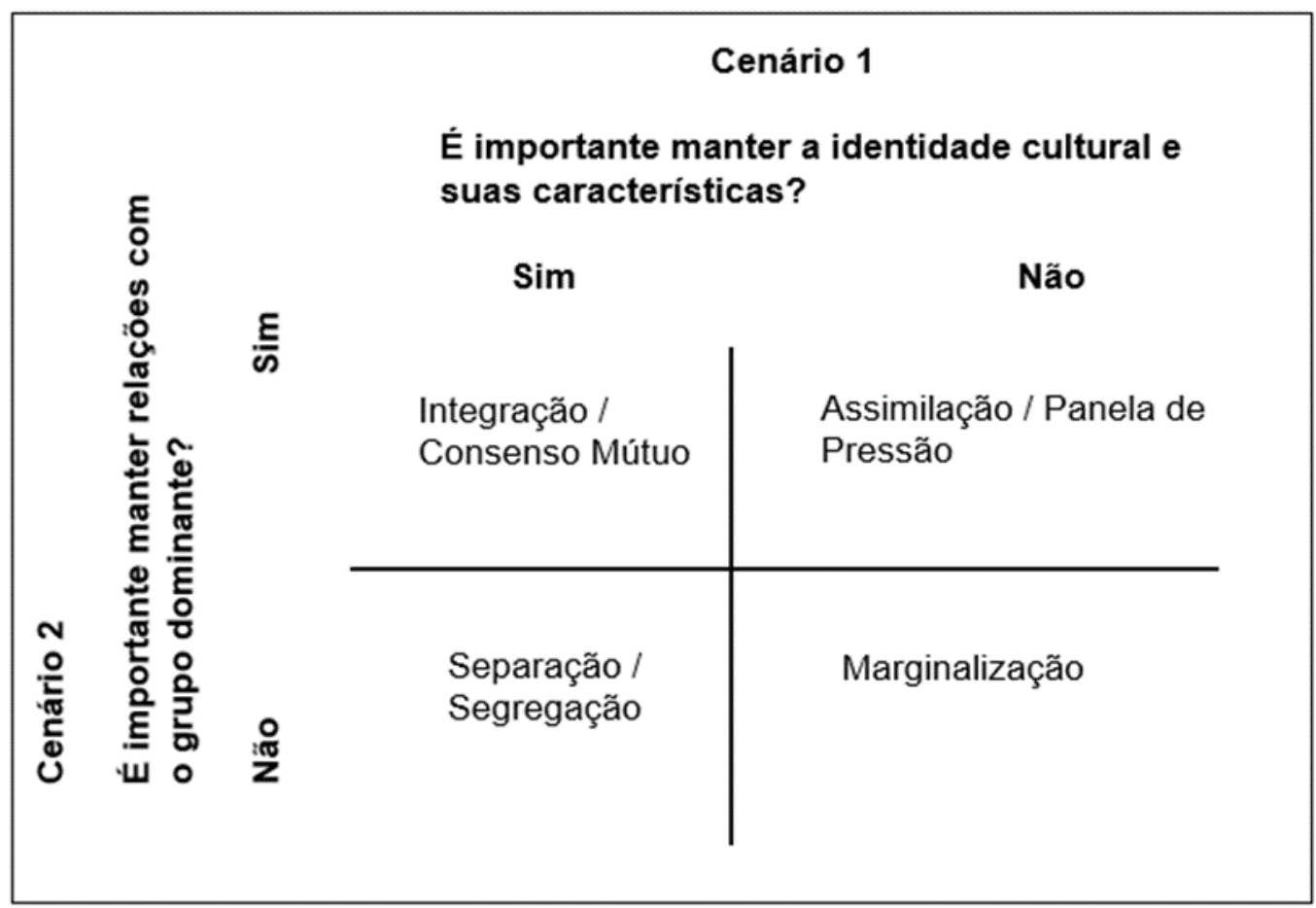

Figura 1 - Estratégias de Aculturação de Berry (1997).

Outro estudo sobre as estratégias de mudança cultural em fusões e aquisições foi criado por Barros (2003) seguindo a referência dos autores Marks \& Mirvis (2001) para analisar cinco possibilidades de integração conforme abaixo. O modelo avalia os níveis de mudança tanto na empresa adquirida quanto na adquirente.

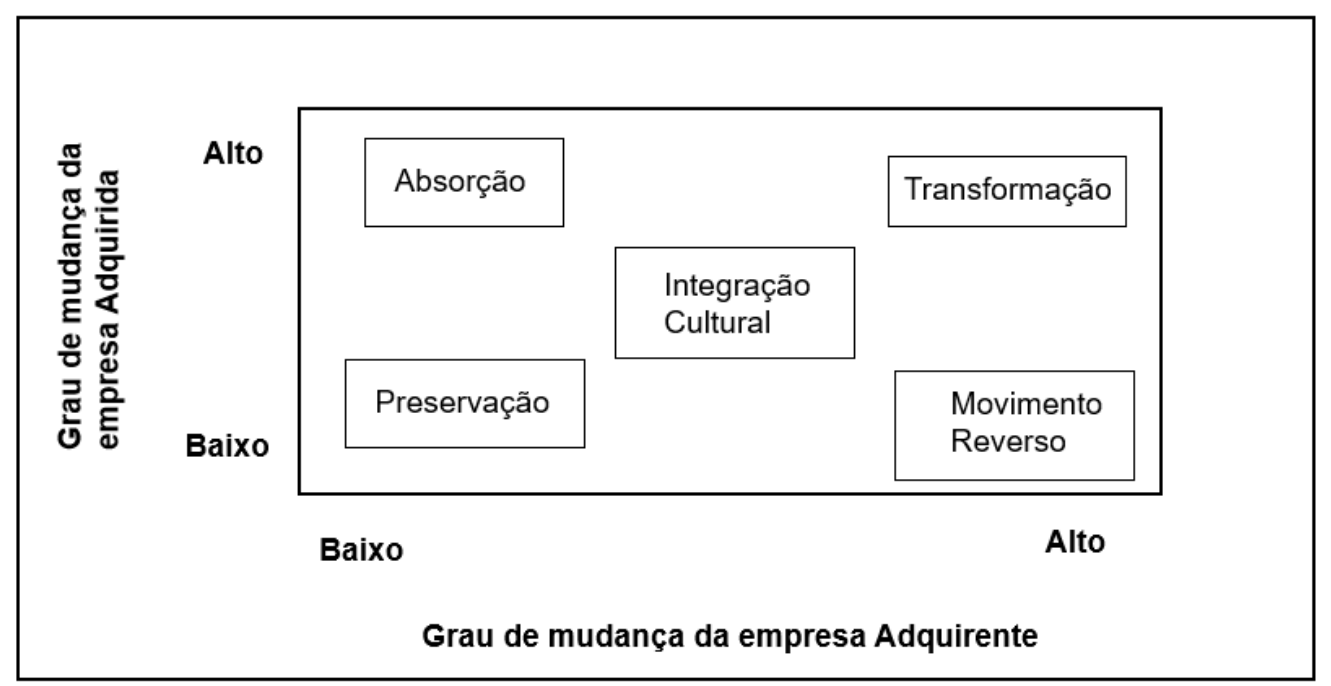

Figura 2 - Estratégias de Integração Cultural de Barros (2003). 
Quando o nível de mudança da empresa adquirida é alto e o da empresa adquirente é baixo, a estratégia adotada segundo o modelo é a de Absorção, pois a que foi comprada terá que se ajustar à outra. Porém, quando os níveis são os opostos dos citados acima, há um movimento reverso e a empresa que foi comprada determinará as regras.

Já quando o grau de mudança é alto para ambas as empresas, a estratégia estabelecida é a de Transformação, pois as duas terão que operar de formas diferentes. Por outro lado, quando as duas possuem níveis de mudança baixos, a estratégia é a de Preservação, em que a empresa adquirida continua independente.

A integração cultural, segundo Barros (2003), será a estratégia escolhida quando houver um somatório das duas empresas, onde serão adotados os melhores procedimentos de cada uma.

\section{5 \\ Mudanças nas equipes após F\&A}

O escritor e professor de comportamento organizacional de Harvard, John Gabarro (1992), realizou um estudo sobre a formação de lideranças em seu livro chamado de "The Dynamics of Taking Charge" (1987). Esta pesquisa analisou as mudanças ocorridas nas equipes após uma fusão ou aquisição nos Estados Unidos. John descobriu que, após estudar quatorze líderes executivos e seus gerenciamentos de formação de novas equipes, em média, leva-se dois anos e meio para o estabelecimento de liderança e conquista dos membros do time.

Além disso, o escritor observou que os três a seis primeiros meses da posse de um novo líder determinam todo o processo de desenvolvimento de um novo time. Por isso, é necessário que as lideranças ajam rapidamente e assertivamente no entendimento de seus subordinados desde o início.

Ainda dentro do estudo de John Gabarro (1992), o mesmo cita que a formação de equipes após uma fusão ou aquisição é complicada quando há mudanças na estrutura da liderança da organização. O escritor cita quatro fatores que influenciam esta atividade: um novo chefe, novos pares (colaboradores na mesma equipe), novas formas de realizar o trabalho e novos padrões de poder. 
O primeiro fator esclarece que o surgimento de um novo chefe gera tensão em uma equipe, pois os subordinados disputam por visibilidade e influencia. $\mathrm{O}$ conflito pode possuir ainda mais impacto quando o cargo do novo chefe poderia ser ocupado por algum membro da equipe ou quando este novo membro vem de outra empresa. O segundo fator, diz que quando um time é formado por funcionários de ambas as empresas, é comum que os membros que pertenciam a mesma empresa juntem-se em grupos.

Já o terceiro fator explica que os membros da empresa adquirida precisam se adaptar as mudanças e aprender as novas políticas, o que contribui para uma tendência dos funcionários em confiar no que já sabem. O último fator de influência ressalta que os líderes precisam estabelecer ou reestabelecer suas autoridades e níveis de influência entre seus subordinados. Pode ser difícil para um executivo obter confiança vindo de uma outra empresa e ainda mais quando os funcionários enxergam sua posição como inferior em função da combinação entre as empresas.

\subsection{1}

\section{Etapas para a formação de novas equipes}

Os pesquisadores e autores Mitchell Marks e Philip Mirvis escreveram em 1992 um artigo sobre como os líderes lidam com as angústias e conflitos após uma fusão ou aquisição e conseguem transformar os "sobreviventes" em equipes eficientes. Todos os grupos passam por etapas até o desenvolvimento de uma equipe. Os responsáveis por este processo precisam lidar com três necessidades de seus membros: as pessoas precisam se sentir desejadas e possuir um afeto emocional com a missão do time; esperança no potencial da equipe e sentimento de confiança tanto nos demais membros quanto individualmente.

Abaixo, os estágios e dimensões que ocorrem em um processo de formação de novas equipes em F\&A segundo os autores. 


\begin{tabular}{|c|c|c|c|}
\hline Dimensão & Estágio 1 & Estágio 2 & Estágio 3 \\
\hline \multirow{2}{*}{ Papel do Líder } & $\begin{array}{c}\text { Processo de formação } \\
\text { da equipe }\end{array}$ & \multirow{2}{*}{$\begin{array}{c}\text { Estabelecer e definir novas } \\
\text { normas }\end{array}$} & \multirow{2}{*}{$\begin{array}{c}\text { Motivar a } \\
\text { performance }\end{array}$} \\
\hline & Estabelecer a expectativa & & \\
\hline $\begin{array}{c}\text { Problemas } \\
\text { enfrentados pelos } \\
\text { membros da equipe }\end{array}$ & $\begin{array}{c}\text { Questionamento } \\
\text { psicológico: "Eu quero } \\
\text { fazer parte disto?" }\end{array}$ & Integração entre as culturas & $\begin{array}{l}\text { Confiança na equipe: } \\
\text { "Nós confiamos uns } \\
\text { nos outros?" }\end{array}$ \\
\hline \multirow{3}{*}{$\begin{array}{l}\text { Fontes de } \\
\text { resistência }\end{array}$} & $\begin{array}{l}\text { Falta de clareza na } \\
\text { missão e propósito }\end{array}$ & Apego aos processos anteriores & $\begin{array}{c}\text { Conflito entre as } \\
\text { novas e antigas } \\
\text { maneiras de realizar } \\
\text { o trabalho }\end{array}$ \\
\hline & \multirow{2}{*}{$\begin{array}{c}\text { Sentimento de estar "em } \\
\text { teste" }\end{array}$} & Conflitos internos & $\begin{array}{l}\text { Diferentes padrões } \\
\text { de performance }\end{array}$ \\
\hline & & Pressão dos colegas & $\begin{array}{l}\text { Diferentes visões } \\
\text { sobre diversidade }\end{array}$ \\
\hline \multirow{2}{*}{$\begin{array}{l}\text { Combatendo a } \\
\text { resistência }\end{array}$} & $\begin{array}{c}\text { Novo recrutamento de } \\
\text { pessoas }\end{array}$ & $\begin{array}{l}\text { Negociar cargos e } \\
\text { responsabilidades }\end{array}$ & \multirow{2}{*}{$\begin{array}{l}\text { Valorizar a } \\
\text { diversidade na } \\
\text { equipe }\end{array}$} \\
\hline & $\begin{array}{c}\text { Houve resistência na } \\
\text { equipe? }\end{array}$ & Controle do choque cultural & \\
\hline
\end{tabular}

Figura 3 - Os estágios na formação de novas equipes em F\&A (Mirvis \& Marks, 1992)

A primeira etapa na construção de novos times começa com o estabelecimento das expectativas por parte das lideranças. Durante este processo, os membros da equipe passam por uma avaliação interna, onde devem questionar se desejam de fato fazer parte deste novo time ou não. Os funcionários precisam saber quais são os propósitos e como isto afetará o desempenho da empresa como um todo. Além disso, pode haver o sentimento de que os mesmos estão sob avaliação de sua gerência e que devem provar que são capazes, caso haja tal afirmação, haverá competição e até mesmo desistências.

Para controlar estas tensões, existem algumas medidas que os líderes podem tomar para formarem seus times, como um novo recrutamento, cuidado extra com o ego dos funcionários (algumas pessoas necessitam de confirmação de seu mérito após uma F\&A para não acharem que estão sendo testados) e maiores exigências nas avaliações de desempenho.

O segundo passo é o desenvolvimento dos cargos e das lideranças dentro de uma equipe para cada atividade. Neste caso há três fatores que influenciam este processo, um deles é o fato de que os funcionários podem continuar "presos" em realizarem o trabalho da maneira que faziam anteriormente, outro ponto são os conflitos internos entre os novos pares para ganharem poder e influência com o chefe e por fim podem haver atritos quando um novo chefe não respeita as regras informais criadas pelos funcionários antigos. 
Para administrar sua equipe, um líder deve negociar com seus colaboradores novas responsabilidades e deveres, após decidido as posições e atividades de cada um. É comum que os funcionários fiquem confusos em relação a quem devem se reportar depois da formação da nova equipe, por isso, a liderança deve esclarecer como será a estrutura de autoridade. Por último, é importante determinar as regras básicas do time, como procedimentos formais a serem adotados e também as normas informais que serão seguidas.

A última etapa, que é essencial para o grupo iniciar o trabalho, é o sentimento de confiança que todos devem possuir no time. Desse modo, poderão atingir níveis de produtividade maiores. Para que isso seja possível, os mesmos terão que aprender novos procedimentos e se adaptarem aos novos sistemas. Além disso, o time precisará compreender os novos padrões de expectativa que seus chefes terão.

Outro ponto de interferência na performance do grupo é a habilidade de lidar com a diversidade. Pode ser difícil para os membros conciliarem as diferenças entre as culturas organizacionais e a forma como seus pares estão acostumados a trabalharem. Para que haja confiança entre os funcionários, os líderes podem adotar as seguintes medidas: agir como um modelo de comportamento a ser seguido pelos colaboradores, recompensar bons desempenhos e ligá-los aos comportamentos desejados e liderar com visão e valores compartilhados.

\section{6}

\section{Escolha dos Modelos para Aplicação da Pesquisa}

Os modelos escolhidos para a aplicação da pesquisa deste trabalho a partir da literatura acima, foram os de Marks \& Mirvis (1992) e o de Barros (2003). Estes modelos buscam analisar o processo de formação de novas equipes durante processos de Fusões e Aquisições e as estratégias de integração cultural, respectivamente. Por isso, contribuem para a compreensão dos objetivos propostos neste estudo. 


\title{
3 \\ Metodologia
}

Diante dos objetivos propostos no Capítulo 1, foi realizado um estudo de caso para compreender os impactos causados na integração cultural e na formação de novas equipes com a aquisição da empresa Lamson pela empresa Energy Global (EG). Para atender a tais objetivos, foi escolhida a pesquisa qualitativa exploratória, que levantou dados a partir das opiniões e declarações de indivíduos, de modo a entender suas percepções e experiências. O estudo foi feito por meio de um estudo de caso além do recolhimento de diversas fontes de informação. Para Yin (2001):

\begin{abstract}
Um estudo de caso é uma investigação empírica que investiga um fenômeno contemporâneo dentro de seu contexto da vida real, especialmente quando os limites entre o fenômeno e o contexto não estão claramente definidos. A investigação de estudo de caso enfrenta uma situação tecnicamente única em que haverá mais variáveis de interesse do que pontos de dados, e, como resultado, baseia-se em várias fontes de evidências, com os dados precisando convergir em um formato de triângulo, e, como outro resultado, beneficia-se do desenvolvimento prévio de proposições teóricas para conduzir a coleta e a análise de dados.
\end{abstract}

Para analisar as questões propostas nos objetivos deste trabalho, foram utilizadas diversas fontes de informação, como dados secundários que serviram para a construção do Capítulo 2, documentos divulgados pela empresa compradora após a aquisição e site oficial da empresa. Além disso, foram recolhidos dados primários para esta análise, por meio de entrevistas com os funcionários de ambas as empresas.

As entrevistas foram realizadas com duas equipes que foram formadas a partir da aquisição. O escopo do questionário utilizado na pesquisa com os membros das duas equipes baseou-se no modelo de formação de novas equipes em F\&A de Marks \& Mirvis de 1992, encontrado no Apêndice A. Além disso, foi realizada uma entrevista com um gerente de Recursos Humanos da EG responsável pela concretização da integração entre as duas empresas. Durante a entrevista com o gerente, foi utilizado o modelo de Estratégias de Integração Cultural de Barros (2003), para identificar a estratégia de integração cultural adotada pela empresa compradora, apresentado no Capítulo 2. 
A primeira entrevista foi realizada com uma Trainee da área financeira que o autor já conhecia anteriormente, e por isso a escolha de entrevistar a equipe desta entrevistada. Outro fator que contribuiu para a escolha desta equipe foi o fato de haver pessoas de ambas as empresas. A segunda equipe foi escolhida por recomendação de uma das entrevistadas, em que havia pessoas que vieram de ambas as empresas para a nova equipe.

Abaixo, o perfil de cada entrevistado para a coleta de dados:

\begin{tabular}{|c|c|c|c|c|l|c|c|}
\hline Entrevistado & Equipe & Idade & Sexo & $\begin{array}{c}\text { Tempo } \\
\text { de } \\
\text { empresa }\end{array}$ & \multicolumn{1}{|c|}{ Cargo } & Área & $\begin{array}{c}\text { Empresa } \\
\text { de orígem }\end{array}$ \\
\hline 1 & $\mathrm{~A}$ & 40 & $\mathrm{~F}$ & 11 & $\begin{array}{l}\text { Senior Finance } \\
\text { Staff Manager }\end{array}$ & Finanças & $\mathrm{A}$ \\
\hline 2 & $\mathrm{~A}$ & 33 & $\mathrm{~F}$ & 8 & $\begin{array}{l}\text { Sales/Bid } \\
\text { Support Analyst }\end{array}$ & Finanças & $\mathrm{B}$ \\
\hline 3 & $\mathrm{~A}$ & 28 & $\mathrm{~F}$ & 3 & Trainee & Finanças & $\mathrm{A}$ \\
\hline 4 & $\mathrm{~B}$ & 42 & $\mathrm{M}$ & 13 & $\begin{array}{l}\text { Senior Staff } \\
\text { Manager }\end{array}$ & $\begin{array}{c}\text { Project } \\
\text { Management }\end{array}$ & $\mathrm{A}$ \\
\hline 5 & $\mathrm{~B}$ & 35 & $\mathrm{~F}$ & 7 & $\begin{array}{l}\text { Document } \\
\text { Management } \\
\text { Specialist }\end{array}$ & $\begin{array}{c}\text { Project } \\
\text { Management }\end{array}$ & $\mathrm{B}$ \\
\hline 6 & $\mathrm{~B}$ & 37 & $\mathrm{M}$ & 16 & $\begin{array}{l}\text { Leadership } \\
\text { Specialist }\end{array}$ & $\begin{array}{c}\text { Project } \\
\text { Management }\end{array}$ & $\mathrm{B}$ \\
\hline 7 & - & 50 & $\mathrm{M}$ & 10 & $\begin{array}{l}\text { Human } \\
\text { Resources } \\
\text { Manager }\end{array}$ & $\begin{array}{l}\text { Recursos } \\
\text { Humanos }\end{array}$ & $\mathrm{A}$ \\
\hline
\end{tabular}

Figura 4 - Perfil dos entrevistados

\section{1 \\ Seleção do Caso}

Foi selecionada para este estudo, uma empresa multinacional de grande porte, que está presente no Brasil e que atua em mais de oito setores diferentes. Para este trabalho, foi escolhida uma das maiores aquisições desta empresa que ocorreu em 2015, no setor de Energia Elétrica e Renovável. A empresa adquirente foi denominada como Energy Global, e a empresa que foi adquirida, Lamson. Estes nomes são fictícios, para manter discrição sobre a identidade das empresas. 
Desde sua fundação, a EG cresceu por meio de fusões com outras empresas assim como pela compra de outras companhias para desenvolver produtos inovadores e se tornar pioneira em diversos segmentos de mercado. Em 1890, nasce a companhia a partir de uma fusão. A companhia produz desde motores de aviões, equipamentos para hospitais, usinas hidrelétricas, equipamentos para extração de petróleo a análise de dados gerados pela indústria.

A compra em estudo faz parte da divisão de negócios de Energia da empresa, que trabalha no desenvolvimento de soluções em geração de energia. Para tornar-se cada vez mais sustentável, a empresa realizou a aquisição da divisão de negócios da Lamson de Energia para investir em soluções de gás e vapor que são mais eficientes e limpas em comparação aos equipamentos a óleo.

A Lamson está presente no Brasil a 60 anos e após a venda da sua divisão de negócios do setor de Energia, a empresa passou por uma mudança em sua estratégia principal e agora investe no segmento de transportes. 


\section{Análise}

\section{1}

\section{A Aquisição}

A aquisição do negócio de Energia da Lamson custou 9,5 bilhões de dólares, e segundo o CEO da Energy Global, a combinação de ambas as empresas buscou aumentar o valor para os clientes com novas soluções, assim como o valor de mercado da EG. Segundo ele: "A tecnologia e geografia complementar dos ativos da Lamson, irão nos possibilitar a criar mais valor aos nossos clientes e um forte retorno aos acionistas da EG".

Este acordo marcou o maior investimento industrial na história da companhia, em que a estratégia da aquisição foi a de posicionar a Energy Global como uma empresa de tecnologia e infraestrutura. Para alcançar este objetivo, as duas empresas juntaram suas forças nas atividades em que tinham destaque, como a unificação das turbinas a gás da EG com as turbinas a vapor da Lamson que formaram uma usina de ciclo combinado.

Visto isso, houve um aumento de $50 \%$ da base instalada em geração de energia da EG, um dos portfólios mais abrangentes e profundos de energia renovável no mercado, melhorias e fortalecimento na capacidade de suas usinas, assim como em conhecimento para elaboração e financiamento de novos projetos.

\section{2}

\section{Análise dos Resultados}

Os resultados foram estudados a partir do Modelo de Formação de Equipes de Marks e Mirvis citado no Capítulo 2, onde analisou-se os estágios de um processo de formação de uma nova equipe com base em quatro dimensões: 
Papel do Líder, Problemas Enfrentados pelos Membros da Equipe, Fontes de Resistência e Combatendo a Resistência.

\subsection{1}

\section{1․ Dimensão - Papel do líder}

\section{Estágio 1:}

No primeiro estágio do Modelo de Formação de Equipes de Marks e Mirvis, o papel do líder é analisado no processo de decisão para a formação de uma nova equipe. Após as entrevistas com os líderes das equipes estudadas, percebe-se que pessoas de ambas as empresas foram selecionadas para a nova estrutura e que este processo era novo para todos os envolvidos. Além disso, as equipes foram formadas de acordo com as necessidades de cada área.

\footnotetext{
"Esse processo foi novo tanto para o pessoal que veio da Lamson quanto para os da Energy Global que já estavam aqui. A gente conseguiu separar os times de uma forma que fizesse mais sentido e devido a quantidade de pessoas e alinhar qual era a necessidade do negócio". - Líder 1 / Equipe A.
}

Outro ponto durante esta etapa é o estabelecimento das expectativas para os membros da equipe, foi notado que os líderes esclareceram as atividades e os objetivos do novo time:

"Foi feita uma entrevista com cada membro para alinhar as atividades, e depois a gente sentou com o meu chefe para estabelecer os 'targets'”. - Líder 2 / Equipe B.

\section{Estágio 2:}

Na segunda etapa do modelo, o papel do líder é o de definir novas regras e normas, porém, os resultados mostraram que isso não foi realizado. Ao contrário do que o modelo propõe, os líderes não criaram novas condutas, e sim adaptaram os melhores processos de cada lado para a nova equipe, ou mantiveram o padrão global da EG.

"Não, eram perfis diferentes, a maneira que a Lamson trabalhava era de um jeito e o da EG de outro, então tivemos que decidir qual era a maneira de trabalhar daqui por diante. Tinham processos que eram melhores em uma do que na outra e viceversa. Foi uma adaptação de processos, fazendo um 'share de best practices', com o que poderia ser melhorado". - Líder 1 / Equipe A. 


\title{
Estágio 3:
}

Já o terceiro estágio, com a equipe formada, analisa como o líder motiva e incentiva seus membros. Foi percebido que os líderes utilizam os mecanismos que a Energy Global já oferece para incentivar e registrar a alta performance dos funcionários. Os mesmos informaram que fazem uso dos sistemas de recompensas para reconhecer bons comportamentos. Como a EG possui uma cultura de meritocracia, estes sistemas ajudam a avaliação de desempenho. Outra forma de motivação citada foi a de exposição dos membros com os executivos, para que seus trabalhos sejam vistos e reconhecidos.

\begin{abstract}
"A gente tem o processo chamado Above and Beyond aqui na EG. Eu sou uma pessoa muito 'people oriented' e eu aprendi nos meus 11 anos de empresa a ser meritocrática. Eu sempre levo o meu time em reuniões importantes com os nossos superiores para dar mais exposição a todos e isso os motiva muito". - Líder 1 / Equipe A.
\end{abstract}

\subsection{2 \\ 2a Dimensão: Problemas enfrentados pelos membros da equipe}

\section{Estágio 1:}

Esta dimensão estuda os possíveis problemas que os membros subordinados das equipes podem enfrentar durante o processo de formação de uma nova equipe. No primeiro estágio, o lado psicológico dos membros foi estudado, onde foi perguntado se houve um questionamento interno em relação ao pertencimento do novo time.

A Equipe $A$, em que foram entrevistadas pessoas que pertenciam a ambas as empresas, revelou que houve um questionamento interno sobre a nova estrutura, que possuíam dúvidas em relação aos novos procedimentos e até mesmo se seriam bem recebidos:

"Eu questionava se seria bem recebida e como seriam os novos processos. Gera um pouco de desconforto, por mais que eu já conhecesse a Empresa $A$ e já trabalhasse nela há dois anos como estagiária”. - Membro 2 / Equipe A.

Por outro lado, a Equipe $B$, em que foram entrevistadas pessoas que pertenciam a mesma empresa (Lamson), não se questionou. Os membros estavam confiantes de que continuariam realizando de forma eficiente seus trabalhos e que estavam abertos para o novo: 
"Não teve esse momento de questionamento, é como se você entrasse e já estivesse instalado, quando você viu você já estava lá. A única coisa que eu fiz logo de cara, foi que eu queria conhecer antes de tomar alguma decisão. A primeira coisa foi ler todo material que a Energy Global divulgou para a gente sobre a política da empresa, quais eram os valores, eu comecei a ler e conversar com pessoas que já fizeram parte da empresa. Estava bem cabeça e coração aberto para o novo". - Membro 1 / Equipe B.

\section{Estágio 2:}

Os resultados mostraram que houve um choque entre as culturas devido às suas diferenças, como o fato de que a EG valoriza a meritocracia, ao passo de que a Lamson valoriza a hierarquia. O processo de integração cultural ainda está em desenvolvimento, visto que a aquisição possui apenas dois anos de existência. Os membros que vieram da empresa comprada relataram que não sofreram impacto com a diferença cultural e que estão satisfeitos com o processo de integração:

"A EG fez uma programação de passo a passo para ter o menor impacto possível na integração, ela fez vários "waves", então em cada wave ela ia introduzindo alguma mudança e unificando os processos. Dessa maneira o impacto não foi tão grande". - Membro 2 / Equipe B.

Já a Equipe A informou ter notado uma grande diferença cultural entre os funcionários de ambos os lados e que até hoje é possível perceber esta discrepância:

"Foi uma adaptação lenta, bem no dia a dia, não acho que a integração completa tenha acontecido até agora acho que tudo demora". - Membro 2 / Equipe A

\section{Estágio 3:}

Esta etapa do processo descreve como os membros das equipes adquiriram confiança uns com os outros. As entrevistas mostraram um consenso de que houve dificuldade neste sentido, que muitas pessoas precisavam "provar" seu potencial para seus gestores. Uma questão citada que contribuiu com esta dificuldade foi que a aquisição ocorreu durante um período de instabilidade econômica e política no país, e que por isso as pessoas estavam receosas.

"O processo se deu com o tempo, o pessoal da Lamson sabia que a EG era a compradora, então sabíamos que era normal em uma reestruturação a empresa tentar manter as pessoas que ela conhece, o clima de incerteza todo mundo sentia. Mas durante o dia a dia do trabalho, todo mundo mostrando o seu potencial foi gerando confiança no pessoal. Outro problema foi que a fusão aconteceu em um período de crise brutal na economia, então vários projetos foram cancelados e o clima de corte e preocupação era pesado". - Membro 2 / Equipe B. 
A Equipe $B$ relatou que seus membros conseguiram adquirir confiança uns com os outros com o tempo e que seu líder teve grande influência para que o time entrasse em conexão, pois o mesmo identificou o perfil de cada um e foi capaz de fazer com que todos ficassem alinhados. Já a Equipe $A$ não atingiu esta integração rápido, já que os membros que pertenciam a Lamson consideravam hábitos antigos da EG como errados:

"Como a adaptação não rolou logo de cara, eu acho que a confiança vem muito com a sintonia do time. No começo eu cometia muitos erros, eu tinha muitos hábitos que eram da EG e eles não consideravam certos, então isso tudo abalou muito". - Membro 2 / Equipe A.

\subsection{3}

\section{3a Dimensão: Fontes de Resistência}

\section{Estágio 1:}

Após a definição da nova estrutura da equipe, os membros foram questionados se os objetivos foram esclarecidos desde o começo. Todos afirmaram que não possuíam conhecimento profundo do propósito da equipe, e que foram aprendendo com o passar do tempo. A Equipe A sentiu falta de clareza na comunicação por parte da empresa compradora, pois algumas informações foram divulgadas aos funcionários e outras não, como o corte de pessoas, porém a equipe já esperava por isso, visto que em outras aquisições da empresa o mesmo fato ocorreu.

\footnotetext{
"Eu aprendi um pouco na dor, não houve muita clareza na comunicação, poderia ter sido melhor, mas acho que também poderia ter sido melhor da minha parte". Membro 2 / Equipe A
}

Já a Equipe B mostrou-se satisfeita em relação ao esclarecimento dos objetivos e atividades devido ao envolvimento do líder durante o processo. Pois como a nova estrutura era nova para o líder, o mesmo foi construindo as metas e propósitos junto com o time para que todos participassem elaboração da equipe. Os membros afirmaram que desde o começo houve uma reunião com cada um para a definição das atividades e responsabilidades. 
"A EG estava formando uma nova equipe, que não chegou já formada e eu comecei a fazer parte, ela chegou como um conceito que estava em construção. Os objetivos não foram esclarecidos desde o começo porque eu acho que nem ele (Líder) sabia. Mas depois que as coisas foram se construindo, sim, porque ele foi construído os meus objetivos junto comigo, ele me perguntava se eu estava de acordo, então ele foi construído os meus objetivos junto comigo. Depois a gente só formalizou isso na plataforma de RH e aí sim ficou mais claro". - Membro 1 / Equipe B.

Em relação a insegurança, observou-se que pessoas de ambos os lados sentiram-se de tal forma. Quem veio da empresa compradora afirmou que ao trabalhar com pessoas da outra empresa, constantemente eram comparados. Já quem veio da empresa adquirida, informou que sentia maior incerteza sobre a permanência de seus empregos.

\section{Estágio 2:}

Durante a segunda etapa desta dimensão, foram avaliadas questões sobre os hábitos antigos de realizar o trabalho, conflitos internos na equipe e pressão dos membros. Os resultados sobre as formas de realizar as atividades mostraram que todos tiveram que se adaptar aos novos procedimentos, tanto quem veio de uma empresa, quanto da outra.

"A gente usa muitos sistemas, o SAP que era da Lamson e o Oracle que é da EG. Eu ainda faço muita coisa pelo SAP. A metodologia que eu uso no SAP continuou da mesma forma como eu fazia antigamente, mudou o escopo agora que eu mudei de empresa". - Membro 1 / Equipe A.

Outro resultado foi o fato de que algumas áreas tiveram que adotar $100 \%$ dos procedimentos da empresa adquirente após a aquisição e que isto pode ter contribuído para suas permanências na empresa. Conforme dito pela Equipe B:

"Eu mudei totalmente. Abandonei mesmo o jeito antigo, como eu estava com a cabeça e coração aberto eu adotei as novas formas de trabalhar e acho que isso foi um diferencial para poder continuar na empresa". - Membro 1 / Equipe B

Quando questionados sobre conflitos internos nas equipes, todos afirmaram que o único problema encontrado foi o de choque cultural entre as pessoas de empresas diferentes e que a interação demorou para fluir.

Já em relação a pressão entre os membros, notou-se que a Equipe $A$ não sentiu ameaça de perder o emprego, porém devido ao escopo da área e das atividades da área financeira, havia pressão para não cometer erros que impactassem a empresa. 
"Tinha muita pressão, mas também devido ao negócio que a gente trabalha, 'Wind' é um negócio que tem projetos de longo prazo e que são muito caros, quase 2 bilhões de reais, um erro pode impactar muito um projeto". - Membro 2 / Equipe A.

Por outro lado, a Equipe B informou que sentiu ameaça de perder o emprego e pressão de inserção rápida na nova cultura, e que muitas pessoas que vieram da empresa adquirida sentiam-se de tal forma.

"Sim, teve pressão nos que tinham uma função mais alta, pois muitos cargos foram sobrepostos. Por exemplo, muitos sentiram essa insegurança pois sabiam que tinham duas pessoas ocupando a mesma função". - Membro 2 / Equipe B.

\section{Estágio 3:}

Após a avaliação dos hábitos antigos de realizar o trabalho, foi analisada a adaptação aos novos procedimentos e sistemas, diferenças sobre a expectativa de performance e aceitação a diversidade nas equipes. A Equipe $A$ admitiu dificuldade de adaptação aos novos sistemas, principalmente quem já era da Energy Global e passou a utilizar o SAP, pois tiveram que organizar dois prazos de entrega para cada sistema:

"Eu tinha que ter dois 'dead lines', um para o Oracle e outro para o SAP. Então tudo foi mais confuso, mudar o 'midset' e aprender os novos procedimentos". Membro 2 / Equipe A.

Já a Equipe B não sofreu grandes dificuldades, pois seu líder logo no começo introduziu os membros as pessoas importantes de cada novo sistema para que aprendessem da melhor forma possível:

"O meu gestor me apresentou às pessoas que eram importantes nos sistemas que eu passaria a usar, então eu criei um relacionamento com elas desde o ínicio e até hoje tenho uma parceria grande com eles". - Membro 1 / Equipe B.

Em relação a expectativa sobre performance, a Equipe $B$ mostrou-se satisfeita com a forma de avaliação, informando que sempre tiveram clareza de suas metas e que utilizam a ferramenta interna da empresa junto com seu líder para registrar e acompanhar o desempenho.

\footnotetext{
"A gente sempre foi orientado a fazer todas as metas registradas na ferramenta interna da empresa, pois ajudaria na nossa avaliação. Tiveram várias campanhas de melhorias para diminuir custos e tempo de processo, então quando alguém desenvolvia alguma melhoria ela era reconhecida pelo time dentro da ferramenta". - Membro 2 / Equipe B.
} 
Porém, a Equipe $\mathrm{A}$ informou que a expectativa era muito alta e que não havia tolerância a erros.

"A expectativa era muito alta, não tinha muito detalhamento, mas tudo tinha que estar perfeito". - Membro 2 / Equipe A.

Já a aceitação a diversidade foi considerada positiva em ambas as equipes, uma vez que a cultura da empresa compradora valoriza a diversidade, assim como a empresa adquirida também valorizava.

"Na Lamson já era assim e na EG o foco é bem grande nisso, do respeito a diversidade. $O$ pessoal aqui é bem tranquilo, respeita bem. Não existe nenhum tipo de preconceito". - Membro 2 / Equipe B.

\subsection{4}

\section{Dimensão: Combatendo a Resistência}

\section{Estágio 1:}

No primeiro estágio desta dimensão os líderes informaram que devido a nova estruturação muitas pessoas foram demitidas, pois diversos cargos estavam duplicados, ou seja, para uma função específica havia mais de uma pessoa exercendo o mesmo trabalho. Porém, não houve um novo recrutamento e sim o aproveitamento das pessoas de ambas as empresas.

Já em relação a resistência dos membros das equipes, o Líder 1 afirmou que não houve problema em seu time e que existem pessoas de ambos os lados que trabalham juntas e se ajudam. Porém, o Líder 2 informou que houve resistência no começo entre pessoas de outras áreas.

"Como toda aquisição a gente teve uma reestruturação, algumas pessoas foram mandadas embora porque tinham muitas posições que eram duplicadas e tinha overlap entre as duas empresas". - Líder 1 / Equipe A.

\section{Estágio 2:}

Os níveis hierárquicos e responsabilidades de cada membro das equipes foram esclarecidos pelos líderes com todos desde o começo, segundo os líderes entrevistados. Além disso, como a Lamson possuía uma estrutura com muitos níveis hierárquicos, foi necessária uma adaptação a estrutura da Energy Global. 
Já o processo de adaptação com a nova cultura foi lento, devido as diferenças de ambas as empresas, assim como a complicação de que a EG possui uma cultura específica e exige rápida absorção. Outro ponto que dificultou este processo, foi o fato de que a aquisição ocorreu em um período de crise político-econômica no Brasil e por isso as pessoas estavam inseguras em relação a seus empregos.

"A gente está passando por uma situação complicada no mercado, de instabilidade econômica, então isso também não ajuda. Teve gente que se adaptou rápido e gente que demorou, a cultura da EG não se aprende em dois dias. A EG está sempre mudando. Mas a adaptação do meu time foi muito boa". - Líder 2 / Equipe B.

\section{Estágio 3:}

A diversidade de ambas as equipes não dificulta o trabalho e o dia a dia dos membros, segundo os líderes, todos trabalham bem juntos apesar das diferenças. Conforme dito anteriormente, a EG valoriza a diversidade nas equipes e exige que todos tenham respeito uns com os outros.

"Tem diversidade mas de gênero, são 6 homens e 6 mulheres, contando os estagiários, mas não temos problema nenhum, inclusive eu tenho duas pessoas na equipe que estão de licença de maternidade e foi bem tranquilo". - Líder 1 / Equipe A.

\section{3}

\section{Síntese dos Resultados}

Após realizada a análise das entrevistas, pode-se concluir que a Equipe $B$ apresentou grau de integração superior em relação a Equipe A. De acordo com as respostas, as pessoas da Equipe B não sofreram grande impacto com a aquisição e se adaptaram facilmente a nova cultura. Além disso, os membros revelaram que não houve dificuldade de inserção com a nova empresa e os novos colegas de trabalho.

Outro ponto que foi informado pela Equipe $B$, foi o fato de que a aquisição ocorreu durante um período de crise política econômica no país, e que por isso a preocupação existente nos funcionários de perderem seus empregos se deu por este motivo e não necessariamente pela ameaça da aquisição.

Já a Equipe A, apresentou dificuldades de integração com a aquisição e formação de equipe. Os membros informaram que os objetivos da nova equipe 
não foram esclarecidos devidamente e por isso o processo de adaptação com os novos colegas foi lenta. Porém, após os dois anos da nova empresa, a equipe conseguiu atingir um nível de integração adequado e correspondente com o esperado pela empresa.

Vale ressaltar que os membros entrevistados da Equipe B vieram da mesma empresa (Lamson) e os membros entrevistados da Equipe A vieram de empresas diferentes. Esta diferença pode ter impactado o processo de integração e adaptação da equipe. O quadro abaixo, mostra a síntese dos resultados de cada equipe em cada dimensão e estágio do modelo utilizado:

Equipe A:

\begin{tabular}{|c|c|c|c|}
\hline Dimensão & Estágio 1 & Estágio 2 & Estágio 3 \\
\hline Papel do Líder & $\begin{array}{l}\text { Cumpriu o } \\
\text { esperado }\end{array}$ & $\begin{array}{l}\text { Não cumpriu o } \\
\text { esperado }\end{array}$ & $\begin{array}{l}\text { Cumpriu o } \\
\text { esperado }\end{array}$ \\
\hline $\begin{array}{l}\text { Problemas } \\
\text { enfrentados }\end{array}$ & $\begin{array}{c}\text { Houve } \\
\text { questionamento } \\
\text { interno }\end{array}$ & $\begin{array}{c}\text { Nota diferença } \\
\text { cultural }\end{array}$ & $\begin{array}{l}\text { Dificuldade de } \\
\text { confiança }\end{array}$ \\
\hline Fontes de resistência & $\begin{array}{l}\text { Falta de clareza } \\
\text { sobre os objetivos }\end{array}$ & Sofreu pressão & $\begin{array}{l}\text { Dificuldade com } \\
\text { os novos } \\
\text { sistemas }\end{array}$ \\
\hline Combate a resistência & $\begin{array}{c}\text { Aproveitamento de } \\
\text { pessoas }\end{array}$ & $\begin{array}{c}\text { Adaptação em } \\
\text { desenvolvimento a } \\
\text { cultura }\end{array}$ & $\begin{array}{c}\text { Valoriza } \\
\text { diversidade }\end{array}$ \\
\hline
\end{tabular}

Figura 5 - Resumo dos resultados da Equipe $\mathrm{A}$

Equipe B: 


\begin{tabular}{|c|c|c|c|}
\hline Dimensão & Estágio 1 & Estágio 2 & Estágio 3 \\
\hline Papel do Líder & $\begin{array}{c}\text { Cumpriu o } \\
\text { esperado }\end{array}$ & $\begin{array}{c}\text { Não cumpriu o } \\
\text { esperado }\end{array}$ & $\begin{array}{c}\text { Cumpriu o } \\
\text { esperado }\end{array}$ \\
\hline $\begin{array}{c}\text { Problemas } \\
\text { enfrentados }\end{array}$ & $\begin{array}{c}\text { Não houve } \\
\text { questionamento } \\
\text { interno }\end{array}$ & $\begin{array}{c}\text { Não nota diferença } \\
\text { cultural }\end{array}$ & $\begin{array}{c}\text { Facilidade de } \\
\text { confiança }\end{array}$ \\
\hline Fontes de resistência & $\begin{array}{c}\text { Clareza sobre os } \\
\text { objetivos }\end{array}$ & Sofreu pressão & $\begin{array}{c}\text { Sem dificuldades } \\
\text { com os novos } \\
\text { sistemas }\end{array}$ \\
\hline Combate a resistência & $\begin{array}{c}\text { Aproveitamento de } \\
\text { pessoas }\end{array}$ & $\begin{array}{c}\text { Adaptação rápida } \\
\text { a cultura }\end{array}$ & $\begin{array}{c}\text { Valoriza } \\
\text { diversidade }\end{array}$ \\
\hline
\end{tabular}

Figura 6 - Resumo dos resultados da Equipe B

\section{4}

\section{Análise da Entrevista com Gerente de Recursos Humanos da Energy Global}

Após as entrevistas com os membros e líderes das equipes, foi realizada uma entrevista com o gerente de $\mathrm{RH}$ responsável pela integração cultural da aquisição para compreender a estratégia adotada pela empresa adquirente. Este gestor trabalhou junto com sua equipe de $\mathrm{RH}$ para determinar o alinhamento entre os funcionários. A análise será feita a partir do Modelo de Estratégias de Integração Cultural de Barros, citado no Capítulo 2.

Além da entrevista, foram analisados documentos sobre a preparação para a integração, assim como sobre as condutas que a empresa passou a seguir após a aquisição. O gerente de Integração informou que antes da junção entre as empresas, foi realizado um questionário sobre cultura e engajamento entre funcionários de ambos os lados para compreender quais pontos deveriam ser cuidados. A pesquisa era composta de 30 perguntas sobre cultura e 10 perguntas sobre engajamento, em que 24.000 funcionários responderam.

Os resultados dos questionários mostraram que os funcionários da $E G$ valorizam o trabalho em equipe, comunicação aberta e os valores da companhia. Ao passo que os funcionários da Lamson valorizam a capacidade gerencial de delegação, comunicação aberta e os valores da companhia. 
A pesquisa revelou que $81 \%$ dos funcionários respondentes, que eram da $E G$, informaram que as equipes que trabalhavam bem, eram reconhecidas por isto, enquanto que apenas $50 \%$ dos funcionários da Lamson concordaram com essa afirmação. Estas pessoas afirmaram que ao receberem feedback de seus gestores, a mensagem era transparente e consistente, enquanto $47 \%$ dos respondentes da Lamson concordaram.

Em relação aos valores da empresa, 80\% dos colaboradores da Energy Global acreditam que as ações de seus líderes estão de acordo com o esperado pela companhia, e 52\% dos colaboradores da Lamson concordaram. Para $74 \%$ dos respondentes da empresa adquirida, era esperado que os mesmos trabalhassem no escritório durante o expediente (home-office não era comum), por outro lado, apenas $12 \%$ dos colaboradores da empresa adquirente concordaram com essa afirmação.

Outra forma que a EG utilizou para avaliar a integração e construir a aliança entre os funcionários, foi por meio de um programa interno chamado "Peers to Peers" (De colegas paras colegas). O programa juntou pessoas de ambos os lados em sessões para contribuir com o alinhamento e engajamento cultural entre as pessoas. Com isso, a Energy Global pode perceber as similaridades e diferenças entre cada lado e trabalhar em ações de melhorias.

As similaridades encontradas com o programa foram que ambas as empresas valorizam a ética, ambiente de trabalho respeitoso, 'networking' com colaboradores e clientes, trabalho em equipe, flexibilidade e conhecimento de negócio. Já as diferenças observadas foram as de tempo de processo de decisão, simplificação de processos, compartilhamento de conhecimento e desenvolvimento de talentos.

Visto isso, a empresa compradora conseguiu estabelecer quais características deveriam permanecer e quais deveriam ser abandonadas, conforme notado no quadro abaixo: 


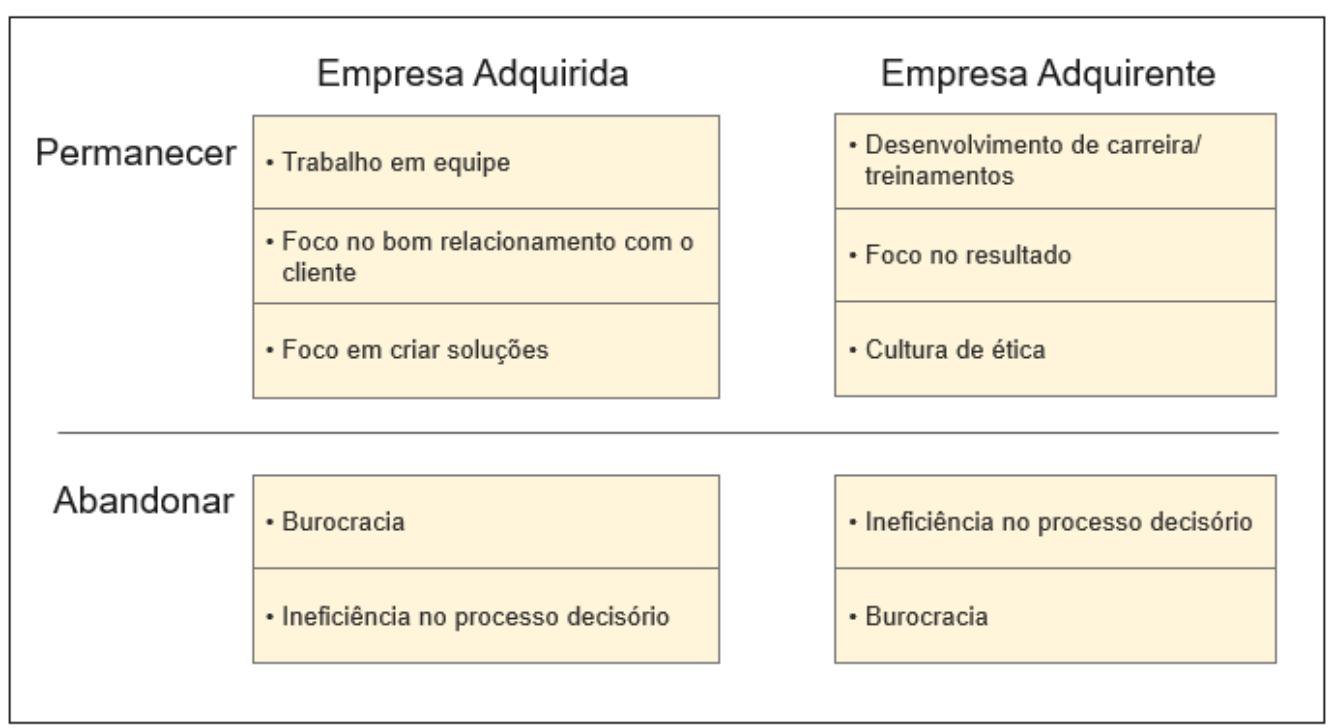

Figura 7 - Descobertas do Programa Peers to Peers

A estratégia para construção de uma aliança forte e comprometida entre as empresas foi elaborada em torno de seis etapas, desde o planejamento da integração ao fechamento da transação. Segundo os documentos analisados, a primeira etapa, foi a de manter os funcionários informados e conectados com a visão do futuro e tornando-os engajados com a aliança. Depois, garantir que os líderes valorizassem a cultura como parte de seus objetivos.

A terceira etapa do processo possuía como propósito a troca de experiências entre colaboradores. As pessoas que eram da empresa adquirente eram incentivadas a ajudarem os demais a se conectarem, conseguirem informações e construir relacionamentos. A EG exigiu isto alegando que a cultura da empresa valoriza o trabalho em equipe e o comprometimento de seus funcionários em ajudarem os outros a alcançarem o sucesso.

Seguindo o processo de integração, a próxima etapa buscou providenciar as ferramentas necessárias que todos os funcionários conseguissem enxergar a visão de longo prazo que a aliança pretendia obter para ser bem-sucedida. Em seguida, houve a criação de uma experiência de boas-vindas para celebrar a integração e engajar todos os colaboradores. Por fim, a EG reforçou a importância de utilizar o comprometimento da empresa em desenvolvimento de lideranças para ajudar os funcionários durante a adaptação a nova cultura. 


\section{5}

\section{Discussão e Considerações finais}

De acordo com as informações obtidas nos documentos e pela entrevista com o gerente de $\mathrm{RH}$, foi notado que a Energy Global utilizou a estratégia de Absorção para a integração cultural entre as duas empresas. Pois, segundo a entrevista, a cultura da empresa adquirida era tradicional, valorizava os níveis hierárquicos e não possuía foco em resultados. Ao passo de que a EG possui foco em resultado, meritocracia e inovação, características que permaneceram na empresa.

Por isso, analisando as entrevistas dos membros e líderes das equipes, documentos da empresa e entrevista com o gerente de Recursos Humanos da empresa compradora, pode-se afirmar que o grau de mudança da empresa Adquirida foi alto, enquanto que o grau de mudança da empresa Adquirente foi baixo. Portanto, segundo o Modelo de Estratégias de Integração Cultural de Barros, a estratégia adotada pela EG após a aquisição da Lamson foi a de Absorção.

Esta estratégia é esperada, visto que a empresa compradora já passou diversas vezes por processos de aquisições e fusões com outras empresas e até hoje conseguiu manter sua cultura forte. Além disso, os próprios funcionários entrevistados que vieram da empresa adquirida, informaram que a cultura da Energy Global estava de acordo com seus valores e crenças pessoais, diferentemente da cultura da Lamson. 


\section{5 \\ CONCLUSÃO}

A análise dos modelos apresentados sobre processo de formação de novas equipes em F\&A e de estratégia de integração cultural contribuiu com o entendimento dos impactos causados pela aquisição deste estudo de caso, tanto nos funcionários quanto no alinhamento cultural das empresas.

Os resultados observados estão alinhados com as premissas citadas no referencial teórico deste trabalho sobre as mudanças após $F \& A$ nas equipes, em que levam-se em torno de dois anos e meio para a integração e adaptação de um novo time (apud Marks \& Mirvis, 1992). Visto isto, conclui-se que a Energy Global está dentro deste perfil, já que a aquisição da Lamson completou dois anos este ano e que a empresa está no caminho de atingir a integração cultural desejada.

Outra premissa deste estudo alinhada com os resultados é o fato de que o líder possui um papel essencial para o sucesso do desenvolvimento da equipe, e que por isso, é preciso que o mesmo consiga rapidamente compreender as necessidades e diferenças de cada membro e agir assertivamente nas ações de melhorias e integração de todos (apud Marks \& Mirvis, 1992).

Este ponto foi citado pela Equipe B entrevistada, pois seu líder foi a chave de sucesso para que os membros fossem capazes de se adaptarem com a nova cultura rapidamente, assim como o mesmo construiu os objetivos da equipe junto com todos os membros e apresentou cada um para as pessoas importantes da empresa que trabalhariam junto com eles.

Vale ressaltar que há limitações dentro desta análise, pois foram entrevistadas duas equipes que possuem experiências e opiniões particulares e que não são as mesmas para todos os funcionários da empresa. Além disso, cada equipe possui uma dinâmica de trabalho única e diferente das demais. Outro ponto importante é o fato de que este tipo de pesquisa não reflete todas as dificuldades vivenciadas no dia a dia.

As recomendações sugeridas para a empresa e para suas lideranças sobre gerenciamento de equipes com perfis diferentes tanto para esta aquisição como para futuras aquisições são listadas abaixo. Para cada perfil de equipe existem necessidades distintas a serem observadas. Estas recomendações foram selecionadas a partir do livro "Leading Across New Borders" de Ernest Gundling de 2015. 
a) Equipes Independentes:

a.1) Abertura para expressarem suas opiniões e ideias

a.2) Processo decisório rápido

a.3) Autonomia no trabalho

b) Equipes que tomam risco:

b.1) Progresso visível

b.2) Flexibilidade de processos e tarefas

b.3) Tolerância ao erro

c) Equipes Igualitárias:

c.1) Líderes precisam demonstrar como cada membro gera valor ao time

c.2) Comunicação informal e debates abertos

c.3) Interação entre os membros de forma fluída

d) Equipes que valorizam o networking:

d.1) Tempo para desenvolvimento de relacionamentos

d.2) Comprometimento de longo-prazo

d.3) Flexibilidade no alcance de resultados

Estes estilos de equipes estão de acordo com a cultura da Energy Global e com as opiniões dos entrevistados, por isso identificar as necessidades que cada estilo de equipe valoriza é importante para que os líderes da empresa consigam integrar os membros de suas equipes durante processos de aquisições futuros e até mesmo motivar o trabalho em equipe de todos.

Por fim, pode-se concluir que a integração cultural e o alinhamento entre as equipes são fundamentais para um desenvolvimento bem-sucedido de uma Fusão ou Aquisição. Entretanto, estas não são atividades simples e que acontecem rapidamente, conforme visto neste caso, mesmo após dois anos de integração completa, ainda existem resistências. Por isso, os líderes devem trabalhar em conectar e alinhar seus funcionários desde o começo para que este processo tenha menos impacto tanto na equipe quanto na empresa em geral. 


\section{REFERÊNCIAS BIBLIOGRÁFICAS}

BERRY, John W. Immigration, acculturation, and adaptation. Applied Psychology: an International Review, Chicago, v. 46, n. 1, p. 5-68, 1997.

BRANDÃO, Hugo Pena et al. Gestão de pessoas como fator de sucesso na incorporação da nossa caixa pelo banco do Brasil. RAC, Rio de Janeiro, v. 17, n. 5, p. 598-619, 2013.

CAMARGOS, Marcos Antônio de; BARBOSA, Francisco Vidal. Fusões e aquisições de empresas brasileiras: criação de valor e sinergias operacionais. ERA, São Paulo, v. 49, n. 2, p. 206-220, 2009.

CAMARGOS, Marcos Antônio de; CAMARGOS, Mirela Castro Santos. Mapeamento da produção científica sobre fusões e aquisições na literatura nacional, 1994 a 2014. Revista Gestão e Tecnologia, Pedro Leopoldo, v. 15, n. 3, p. 101-137, 2015.

GARLICHS, Moritz. The concept of strategic fit. Leiozig: Diplomica, 2010.

HOFSTEDE, G. et al. Measuring organizational cultures: a qualitative and quantitative study across twenty cases. Administrative Science Quarterly, Chicago, n. 35, p. 286-316, 1990.

GUNDLING, Ernest. Leading Across New Borders. Disponível em: < https://learning.aperianglobal.com/portal/globaladvice.cfm?uid=D7FDDE02510B1 F6F293BB4BFC80D617C> Acesso em: 01 Novembro, 2017.

HOMEM, Ivana Dolejal et al. A gestão de pessoas e seus mecanismos de sedução em um processo de aquisição. Revista de Administração Contemporânea, Curitiba, v. 13, n. 2, 2009.

LAUERMANN, Lucas Alan Welter. Nosso jeito de fazer: nasce a nova cultura organizacional do Itaú Unibanco. 2012. 80 f. Trabalho de Conclusão de Curso (Graduação em Administração) - Universidade Federal do Rio Grande do Sul, 2012.

MARKS, M. L.; MIRVIS, P. H. Making mergers and acquisitions work: strategic and psychological preparation. The Academy of Management Executive, Washington, v. 15, n. 2, p. 80-92, 2001.

Rebuilding after the merger: dealing wih survivor sickness. Organizational Dynamics, Washington, v. 21, n. 2, p. 18-32, 1992.

MINTZBERG, H. Safári da estratégia: um roteiro pela selva do planejamento estratégico. Porto Alegre: Bookman, 2000. 
PEREIRA, Rodrigo Carlos Marques et al. Estratégia de integração de cultura nos processos de fusões e aquisições para a sustentabilidade das operações: o caso de uma empresa industrial no ramo de pneumáticos. In: SIMPÓSIO DE ENGENHARIA DE PRODUÇÃO, 13., 6 a 8 nov. 2006, Bauru. Anais... Bauru: SIMPEP, 2006.

RHINOW, G. O Desafio de gestão da mudança em combinações empresariais: a indústria de ciências da vida. Tese (Doutorado em Economia) Universidade de São Paulo, São Paulo, 2006.

RUSSO, Giuseppe Maria. Diagnóstico da cultura organizacional. Rio de Janeiro: Campus, 2010.

SANTOS, Guilherme; TOMEI, Patricia Amelia. Análise quantitativa da estratégia de integração cultural da fusão das empresas $Y$ e Z. In: CONGRESSO NACIONAL DE EXCELÊNCIA EM GESTÃO, 11., 13 a 14 ago., 2015. Anais... Rio de Janeiro: Inovarse, 2015.

SAYÃO, Anna Carolina Maia et al. Mudanças na cultura pós-aquisição: o caso da empresa alfa. In: ENCONTRO DA ANPAD, 30., 23 a 27 set. 2006, Salvador. Anais... Salvador: ANPAD, 2006.

SCHEIN, E. H. Organizational culture. American Psychologist, New york, v. 2, n. 45, p. $109,1990$.

SILVA JÚNIORR., A. B.; RIBEIRO, A. H. R. Parcerias e alianças estratégicas. In: TANURE, B. (Org.). Fusões, aquisições e parcerias. São Paulo: Atlas, 2001. p. 89-102, 2001.

TANURE, Batania; CANÇADO, Vera L. Fusões e aquisições: aprendendo com a experiência brasileira. RAE, São Paulo, v. 45, n. 2, p. 10-22, 2005.

THOMSON REUTERS. Financial and risk. [2017]. Disponível em: <https://financial.thomsonreuters.com/en.html>. Acesso em: 9 nov. 2017.

VASCONCELOS, Flávio C.; CYRINO, Álvaro B. Vantagem competitiva: os modelos teóricos atuais e a convergência entre estratégia e teoria organizacional. RAE, São Paulo, •v. 40, • n. 4, p. 20-37, 2000.

VIANA, Bruno Alves et a. Fusões e aquisições: os choques das culturas organizacionais distintas. In: SIMPÓSIO DE EXCELÊNCIA EM GESTÃO E TECNOLOGIA, 11., 22 e 23 out. 2014, Rio de Janeiro. Anais... Rio de Janeiro: AEDB, 2014.

YIN, Robert K. Estudo de caso: planejamento e métodos.2. ed. Porto Alegre: Bookman, 2001. 


\section{Apêndice}

\section{Roteiro do Questionário das Entrevistas}

1) Dados básicos:

Nome:

Idade:

Sexo:

Cargo:

Tempo de empresa:

Área:

Parte A - Perguntas destinadas aos membros subordinados da equipe

2) Perguntas sobre o "Estágio 1":

a) Você se questionou no começo se realmente queria fazer parte desta equipe ou não?

b) Você conhece o propósito da equipe? Como isto está ligado a missão da empresa?

c) Os objetivos da equipe foram esclarecidos desde o começo?

d) Você se sentiu como se estivesse em "teste", tendo que "se provar" com a formação da nova equipe?

3) Perguntas sobre o "Estágio 2":

a) Você ainda está acostumado/a com as maneiras antigas de realizar suas tarefas?

b) Como foi a integração com a nova cultura?

c) Houve algum tipo de conflito interno com a nova equipe?

d) Houve pressão entre os membros da equipe?

4) Perguntas sobre o "Estágio 3":

a) Como foi sua adaptação aos novos procedimentos e sistemas?

b) Como ocorreu o processo de adquirir confiança nos demais membros da equipe?

c) Como são as expectativas sobre performance na equipe? 
d) Como seu time lida com a diversidade?

e) Como foi a adaptação a nova cultura?

Parte B - Perguntas destinadas ao líder da equipe:

1) Perguntas sobre o "Estágio 1":

a) Como foi o processo de decisão para a formação da nova equipe?

b) Você estabeleceu as expectativas? Como foi esse processo?

c) Houve um novo recrutamento?

d) Houve resistência por parte dos funcionários? Como você lidou com isso?

2) Perguntas sobre o "Estágio 2":

a) Você precisou estabelecer novas regras e normas?

b) Como foi o processo de integração cultural?

c) Você precisou negociar os cargos e responsabilidades com sua equipe?

d) Você precisou definir normas informais?

3) Perguntas sobre o "Estágio 3":

a) Como você motiva sua equipe?

b) Há algum incentivo ao bom comportamento ou boa performance?

c) Como a diversidade é vista na sua equipe?

d) Como foi a adaptação a nova cultura? 